\title{
Accelerate the Turnover of Agricultural Products Funds to Promote the Development of Agricultural and Rural Economy
}

\author{
Qu Jia, Zhang Yana \\ Xi'an Peihua University, Shaanxi Xi'an, China, 710125
}

Keywords: Agricultural products; capital turnover; promotion; agriculture; rural economy; development

Abstract: Since China is a big agricultural country, agriculture is an important factor affecting China's food security and the speed of national economic development. China's party and government have always attached great importance to the development of agricultural and rural economy. At present, some problems still affect the speed of agricultural and rural economic development. Therefore, it is necessary to thoroughly study these issues and formulate effective solutions to promote the stable and sustainable development of the agricultural and rural economy. This paper analyzes the status of China's agricultural economy in the national economy, studies the problems faced by the emergency development of agriculture and rural areas and the corresponding countermeasures, and puts forward suggestions for promoting the development of agricultural and rural economy.

\section{Introduction}

Agriculture will directly affect food security and food safety. China is a big agricultural country. In the process of China's social and economic development, agricultural and rural economic development has also received extensive attention. How to effectively promote agriculture and rural economic stability and sustainable development is an issue that we need to study in depth. In accordance with the actual situation of agricultural development, China needs to promote the transformation and upgrading of agriculture, improve the level of agricultural mechanization and science and technology, and increase the income of farmers. This is of great significance for building a harmonious society and promoting the stable development of the country.

\section{The position of China's agricultural economy in the national economy}

The agricultural economy is an important part of China's national economy, and its development level will not only affect social stability, but also affect China's social and economic development. Since ancient times, China has become a big agricultural country. The level and speed of agricultural and rural economic development will affect the development level and speed of China's national economy, and thus affect China's international status and image. In addition, most of China's population belongs to the agricultural population, and the agricultural labor resources are 
relatively rich. Therefore, promoting the rapid development of agriculture and rural economy plays an important role in realizing the great goal of building a well-off society. In the 18th National Congress of the Communist Party of China, it is clearly stated that China needs to actively solve the problems of agriculture, rural areas, and peasants, increase the income of farmers, promote the transformation and upgrading of agriculture, and promote the stability and sustainable development of agriculture and rural economy. Since China still belongs to the developing countries, in order to promote the stable development of the agricultural economy, it is necessary to upgrade the level of agricultural technology and improve the utilization rate of agricultural resources, thus promoting the rapid development of China's national economy.

\section{Problems facing the urgent development of agriculture and rural areas}

\subsection{The agricultural industry structure is not reasonable enough}

At present, the rural economic development in most areas of China is still dominated by agriculture (mostly planting, mostly planted as food crops), which still belongs to the traditional agricultural category. Most of China's cities and towns have not formed a leading industry, and their promotion to agriculture and rural economy is weak. China's large labor force remains in rural areas and is engaged in crop planting. At this stage, the problem of insufficient resources and insufficient employment rate is still an important factor affecting rural economic development and farmers' income levels. Different from Western countries, China's rural areas still adopt the "one family one" business model, and have not formed large-scale farms, and the level of base development is not high enough, which can no longer meet the needs of social development.

\subsection{Agricultural socialization service mechanism is not perfect}

At this stage, China's agricultural science and technology promotion is not strong enough, which is also an important factor affecting the development of China's agricultural and rural economy. The township agricultural technology promotion institutions in some areas of China lack the necessary technical personnel, and the agricultural science and technology extension workers have shorter working hours, and the township agricultural technology promotion institutions are in a state of suspension for most of the time. In some areas, agricultural science and technology personnel choose to engage in other work. In some areas, the township agricultural technology promotion institutions have relatively poor working conditions, lack of necessary office funds, have not obtained the necessary test bases, and the wages are not high enough. These are all affecting the promotion of township agricultural technology. In addition, the rural agricultural technology promotion institutions in some areas of China still have problems in that the service content is relatively simple and the service management system is not standardized and reasonable. The level of agricultural informatization construction in some areas of China is low, and no sound agriculture has been established. The insurance service mechanism, which is also a factor affecting the development of China's agricultural and rural economy; the investment in agricultural research funds in some areas of China is not enough, resulting in the backwardness of scientific research equipment and the lack of necessary scientific research personnel, resulting in insufficient agricultural science and technology in the region; agriculture in parts of China there are not enough funds for science and technology promotion, and the comprehensive quality level of science and technology extension personnel is not high enough. These are all important factors affecting the speed of agricultural science and technology promotion. 


\subsection{The level of rural industrialization is not high enough}

At this stage, China's urbanization level is not high enough, and there are the following problems in planning and building towns: urban planning is not scientific enough, relevant facilities are not perfect, and the characteristics of the region are not available. The level of urbanization in different regions of China is also different, and there are certain gaps in population size and economic development speed in different regions.

\subsection{Agricultural infrastructure is not perfect}

In recent years, China's emphasis on agricultural and rural economic development has been continuously improved, and a large amount of funds have been invested in the construction of agricultural infrastructure. However, there are still some shortcomings in the construction of farmland water conservancy in some areas. For example: Jilin Province, at this stage, some reservoirs in Jilin Province still cannot fully exert their drought-resisting ability, and pose a great threat to the lives and property of the people. The problem of siltation in irrigation and drainage ditches in some areas of China is unfavorable to the development of China's agricultural and rural economy. Agricultural production activities in some areas of China are still affected by water resources, resulting in low ability of agricultural production to resist natural disasters. The development of agricultural water-saving technology in China is not long. At the same time, due to the problems of soil erosion and high hardening rate of rural roads in China, the development of China's agricultural and rural economy is not fast.

\subsection{Less investment in agricultural products}

In recent years, China's emphasis on agricultural development has been continuously improved, and some regions have formulated urban support policies for rural areas, and formulated policies for rural agricultural machinery subsidies, greenhouse vegetable greenhouse construction, healthy farming communities, and promotion of advanced and applicable technologies. It has a certain role in promoting the stable development of agriculture and rural economy. Although China's investment in agriculture is increasing, there are more funds for agricultural transformation and upgrading, and these funds cannot meet the needs of agricultural transformation and upgrading.

\section{Corresponding countermeasures}

\subsection{Strengthen support for the construction of agricultural science and technology extension system}

At this stage, China's agriculture is in the stage of transformation and upgrading. In order to promote the smooth transformation and upgrading of agriculture, increase farmers' income, and promote the stability and sustainable development of the national economy, it is necessary to actively build an agricultural science and technology extension system and vigorously promote agricultural science and technology, mainly by the following aspects. Start: First, build a specialized agricultural technology promotion team. In order to promote the promotion and speed of agricultural science and technology, each region needs to rely on the level of agricultural development and production needs in the region, and at the county level as a unit, integrate all the teams of agricultural science and technology personnel in the region, and strictly follow the principle of "reasonable layout and function". Scientifically set up agricultural science and technology promotion systems and institutions, improve the working environment of agricultural 
technicians, and improve their salary and treatment, so as to stimulate the enthusiasm of agricultural science and technology extension personnel; second, strengthen agricultural science and technology training, and improve the grasp of new technology by agricultural technology extension personnel comprehension. All regions need to strengthen training activities such as "Great Science Popularization" and "Send Science and Technology to the Countryside" according to the agricultural production needs of the region, so as to enhance the ability of agricultural technology extension personnel to master and understand new technologies. All regions need to train largescale breeding and large-scale agricultural machinery in the region to upgrade their agricultural technology and pass on agricultural technology to more people through these farmers, so as to improve the level of agricultural and rural economic development in the region.

\subsection{Vigorously support the construction of comprehensive production capacity}

Agriculture is an industry closely related to food security and food safety. Promoting the stable development of agriculture is of great significance to ensuring food security and promoting the stable development of the national economy. China's Liaoning, Hebei, Shandong, Jilin and other major grain producing areas need to vigorously develop agriculture, improve the comprehensive grain production capacity of the region, strive to build a national grain core production area, and promote the stable development of the agricultural and rural economy in the region, in order to achieve this goal. The following measures need to be taken: First, strengthen technology research and development to increase food production. In order to ensure food security and increase food production in the region, it is necessary to strengthen research and development of relevant agricultural technologies; second, build high-yield areas for grain and oil production. All provinces in China need to actively build high-yield demonstration films and give full play to their leading role in improving the level of agricultural science and technology in the region. Third, strengthen the prevention and control of crop diseases and insect pests. In recent years, China's environment has changed greatly, and the incidence of crop diseases and insect pests is high. It has become an important art affecting food security and production. Therefore, each region needs to build a major pest control and control institution for crops based on the actual situation in the region. The emergency command and management platform for pest control can effectively improve the speed of information dissemination of crops and improve the control effect of pests and diseases, which is of great significance for ensuring food production safety and production.

\subsection{Formulate a liquidity management post responsibility system}

All regions need to formulate a responsibility system for liquidity management positions, and clarify the responsibilities of various departments and staff members. This can effectively stimulate the enthusiasm of fund management and improve the quality of liquidity management. When formulating the responsibility for liquidity management in different departments, it is necessary to determine the rights of each department and ensure the responsibilities, rights and interests of all departments. For example, the procurement department not only needs to ensure that the enterprise can operate normally, but also needs to properly handle the stagnant backlog and reduce Material loss; the production department needs to shorten the production cycle as much as possible and improve the utilization rate of raw materials, which is of great significance for improving the economic benefits of the enterprise; the sales department needs to actively sell the products of the enterprise and recover the cost of the enterprise as soon as possible. All regions need to pay attention to the management of working capital, and at the same time formulate corresponding management systems to strengthen the management of working capital. In the process of managing liquidity, it is necessary not only to increase the utilization rate of fixed liquidity in the re- 
production process, but also to minimize the use of non-fixed working capital, so as to effectively improve the utilization rate of liquidity in the region and promote economic stability and sustainable development in the region.

\subsection{Speed up the turnover of agricultural products}

The turnover rate of agricultural products is an important factor affecting the economic development speed of agricultural and rural areas in the region. To promote the turnover rate of agricultural products in the region, the following measures must be taken: First, on the basis of ensuring the normal operation of enterprises, the survival of agricultural products should be minimized. Improve the production and sales speed of agricultural products, so as to effectively shorten the survival cycle of rural products; Second, each region needs to scientifically formulate credit policies and collection policies based on the development of agricultural economic development in the region, and quickly recover the credit sales, so as to effectively improve the turnover rate of agricultural products. Third, while ensuring the social benefits of the company, it is necessary to extend the payment time of suppliers, which can also increase the short-term liquidity of enterprises.

\section{Suggestions for promoting agricultural and rural economic development}

\subsection{Improve the quality of farmers}

At present, the comprehensive quality of farmers engaged in agricultural production activities is not high enough, and their ability to master and understand new knowledge and new technologies is not high enough. Therefore, in order to promote agricultural science and technology and promote the stable development of agricultural and rural economy, it is necessary to improve the overall quality of farmers through training. To improve the level of agricultural technology. All regions need to carry out agricultural production technical training according to the actual situation of the region, and the agricultural science and technology personnel of the region should provide professional guidance to farmers; each region needs to set up professional agricultural technology training institutions to enhance farmers' understanding and mastery of agricultural science and technology; Innovate and start a business, and raise the income level of farmers; in addition, each region needs to gradually increase investment in agricultural science and technology research and development, actively research and develop new varieties and new agricultural technology, and plant crops suitable for the region.

\subsection{Improve the utilization of land resources}

Because some farmers are unable to cultivate or go out to work and no one is farming, this part of the cultivated land needs to be transferred on a voluntary and legal basis, using land exchange, renting, etc., and gradually forming a large-scale farm, thus adopting a variety of production methods. In addition, it is necessary to formulate a rural land transfer mechanism to ensure the legitimate rights and interests of farmers who transfer land; each region needs to grow agricultural products such as tea, Chinese medicinal materials, vegetables, food products, etc. suitable for planting in the region according to the actual conditions of the region, thereby improving the utilization of land resources. 


\subsection{Scientifically organize farmers to carry out agricultural production activities}

Some farmers do not understand the market demand for agricultural products, and have not obtained the latest market information. Therefore, there are deviations in the judgment of crop cultivation. The scientific selection of the types and quantities of suitable crops is not scientifically selected, resulting in low or high yields of agricultural products. It will have an adverse impact on farmers' income. Therefore, professional talents need to analyze the market demand for agricultural products, and scientifically guide farmers to choose the most suitable crop planting species and planting quantity, so as to ensure that crop yields are consistent with market demand, which has the important effect of increasing farmers' income and promoting agricultural and rural economic development.

\subsection{Improve the form of agricultural family organization}

In order to achieve the goal of large-scale agricultural production and management, it is necessary to innovate the agricultural production and management model, and promote and develop the "company + farmers" agricultural law model, and actively guide farmers to carry out agricultural production according to market demand. Enterprises can guide farmers to carry out agricultural production activities, and enterprises can employ farmers to carry out agricultural product processing work, which is of great significance for raising farmers' income. In addition, all regions need to strengthen agricultural technology training for village leaders and supply and marketing cooperatives to ensure that agricultural crop seed procurement, crop cultivation, crop sales and other links can receive corresponding services.

\subsection{Transferring rural labor}

First, to strengthen the technological transformation of township enterprises and vigorously promote labor-intensive industries and enterprises, which is of great significance to improving farmers' employment and increasing farmers' income. Second, vigorously develop township enterprises in small towns. The study found that during the development of township enterprises, it will not only promote the economic development of the region, but also increase the employment rate in the region and increase the income of residents in the region. In addition, each region needs to eliminate the household registration control system according to its development, minimize the gap between urban and rural areas, establish and improve the labor mobility mechanism and social security system, and promote the flow of farmers to small towns. Third, strengthen the ideological education of farmers and improve their quality level.

\subsection{Development of agricultural products for electronic commerce}

In some areas, the sales methods of agricultural products are still farmers' markets or wholesale markets. Such sales channels are relatively simple, which is not conducive to increasing farmers' income. Therefore, in order to increase farmers' income, it is necessary to expand the sales channels of agricultural products. With the development of science and technology, the new sales method of e-commerce has gradually emerged, which can break through the constraints of time and space through the Internet and shorten the distance between supply and demand sides. The use of ecommerce to sell agricultural products can shorten the relationship between farmers and demanders, shorten transaction procedures, and reduce the retention time of agricultural products, which is very important to increase farmers' income and promote the rapid development of agricultural and rural economy. 


\section{Conclusion}

To sum up, in order to promote the stable and sustainable development of agricultural and rural economy, it is necessary to speed up the turnover of agricultural products. The main purpose is to increase the cash flow rate and improve the utilization rate of funds; strengthen the management of agricultural products inventory, increase the sales speed of agricultural products, and recycle cost as soon as possible; scientifically formulating credit standards, credit conditions, etc., and improving the turnover rate of accounts, which is of great significance to promoting the stable and rapid development of the agricultural and rural economy.

\section{References}

[1] Xiang Maohong, Zhang Yanchen. Accelerating the Construction of Agricultural Products Brands and Promoting the Development of Modern Agriculture [J]. Gansu Agriculture, 2016(19): 20-21.

[2] Agricultural Products Processing Bureau of the Ministry of Agriculture. Promoting Agricultural Modernization Agricultural Products Processing Industry and Leisure Agriculture have Roles [J]. Jilin Agriculture, 2016(1): 13-13.

[3] Yu Siming. Developing Agricultural Tourism to Promote Sustainable Growth of Rural Economy [J]. Enterprise Herald, 2016(16): 65-66.

[4] Zhang Tianzuo. Promoting the Integration of Rural One, Two and Three Industries in Four Aspects [J]. Jiangsu Rural Economy, 2016(3): 67-67.

[5] Liang Yexing, Dong Yongjian, Zeng Zhihong, et al. Development Status and Countermeasures of Agricultural Products Processing Industry in Chongqing [J]. South China Agriculture, 2017(31):1-4.

[6] He Hongwei. Hubei: Strengthening Agricultural Product Processing Industry and Building a Strong Agricultural Province [J]. Agricultural Products Market Weekly, 2016(27): 36-37. 